\title{
Stendhal, Mérimée et les écrivains romantiques. Le sang, la violence et la mort
}

\section{Nicolas Allard}

\section{(2) OpenEdition}

1 Journals

\section{Édition électronique}

URL : https://journals.openedition.org/studifrancesi/11850

DOI : 10.4000/studifrancesi. 11850

ISSN : 2421-5856

Éditeur

Rosenberg \& Sellier

\section{Édition imprimée}

Date de publication : 1 avril 2018

Pagination : 147-148

ISSN : 0039-2944

\section{Référence électronique}

Nicolas Allard, «Stendhal, Mérimée et les écrivains romantiques. Le sang, la violence et la mort », Studi Francesi [En ligne], 184 (LXII | I) | 2018, mis en ligne le 03 juillet 2018, consulté le 15 novembre 2021. URL : http://journals.openedition.org/studifrancesi/11850 ; DOI : https://doi.org/10.4000/ studifrancesi. 11850

Ce document a été généré automatiquement le 15 novembre 2021.

\section{(c)}

Studi Francesi è distribuita con Licenza Creative Commons Attribuzione - Non commerciale - Non opere derivate 4.0 Internazionale. 


\title{
Stendhal, Mérimée et les écrivains
} romantiques. Le sang, la violence et la mort

\author{
Nicolas Allard
}

\section{RÉFÉRENCE}

Stendhal, Mérimée et les écrivains romantiques. Le sang, la violence et la mort, actes du colloque de Paris-INHA Sorbonne, 5-6 octobre 2007, sous la direction de michel ARROUS, Paris, Eurédit, 2016, 291 pp.

1 Stendhal, Mérimée et les écrivains romantiques. Le sang, la violence et la mort est un ouvrage comportant l'ensemble des actes d'un colloque de Paris-INHA Sorbonne s'étant déroulé les 5 et 6 octobre 2007. Les études, réunies et présentées par Michel ARRous, à qui l'on doit notamment de nombreux articles du Dictionnaire de Stendhal mais aussi la coorganisation du récent colloque «Stendhal et le récit bref» (7 et 8 février 2015), sont au nombre de dix-sept. Elles se focalisent pour la majeure partie d'entre elles sur les œuvres des deux rivaux amicaux qu'étaient alors, en cette première moitié de XIX siècle, Stendhal et Mérimée. D’autres auteurs du XIX siècle sont toutefois convoqués, sans que les études ne se limitent alors, comme le titre du colloque l'indiquait pourtant, aux «écrivains romantiques»: il est ainsi question dans cet ouvrage, de manière il est vrai plus ou moins importante, d'écrivains comme François-René de Chateaubriand, Pétrus Borel, Honoré de Balzac, Victor Hugo, Charles Baudelaire et même Guy de Maupassant. L'ouvrage oscille donc entre une extrême précision et une assez grande généralité du corpus étudié.

2 Ces articles, malgré leur grande diversité, s'appuient tous sur un même constat global: le $\mathrm{XIX}^{\mathrm{e}}$ siècle est l'héritier - consentant ou non - d'une série de violences ayant pour point d'origine la Révolution française. Des phénomènes qui ne relevaient pas a priori d'une sphère littéraire mais bien politique ont ainsi eu une incidence forte et quasi 
immédiate sur l'horizon d'attente du lectorat de l'époque. De fait, que ce soit dans le domaine du roman, du théâtre, du conte ou encore de la nouvelle, les écrivains s'efforcent de donner satisfaction à ce goût récent pour le sang, la violence, la mort, le macabre ou l'atroce.

Max ANDRÉOLI, dans son article Visions romantiques de la Terreur (pp. 1-14), interroge le traitement potentiellement moral de cette esthétique nouvelle. S'appuyant sur des textes de Balzac, Hugo et Dumas père, il démontre que certains auteurs développent une vision optimiste de la Révolution française. La violence déployée apparait dès lors secondaire, le progrès apporté par le changement politique radical étant considéré comme nettement plus important. Sylvain LEDDA, dans Représenter la mort sur la scène romantique: enjeux et polémiques (pp. 15-26), étudie le contexte du spectacle de la mort et de la violence sur la scène romantique. Il estime notamment que le drame romantique ne peut être réellement fantastique dans la mesure où il cultive la véracité historique. Merete GERLACH-NIELSEN, dans son article La violence et la mort chez quelques écrivains danois ou Mérimée au Danemark (pp.27-48), se focalise quant à elle sur la réception danoise des œuvres de Mérimée. On y apprend notamment l'existence de tentatives de censure morale de certains de ses textes, comme la Chronique du règne de Charles IX.

Marie MAKROPOULOU présente une étude consacrée à La Vie errante, œuvre tardive de Maupassant (La "Vie errante" ou la préscience d'une mort heureuse, pp. 49-62). Elle développe dans son article l'idée selon laquelle ce texte manifesterait un abandon du «vouloir-vivre» schopenhauerien en faveur du libre bonheur de la contemplation. Si cette étude ne manque pas d'intérêt, elle ne paraît toutefois pas vraiment entrer dans le programme annoncé par l'ouvrage. Claudie BERNARD s'intéresse pour sa part à la figure de Pétrus Borel, dans un long article intitulé Des loups et des hommes: l'expression de la justice dans "Madame Putiphar" de Pétrus Borel le lycanthrope (pp.63-92). Claudie Bernard émet l'hypothèse selon laquelle le romantisme frénétique de Borel serait une manière de contester les artifices de la civilisation, et de dénoncer les crimes de l'Histoire aussi bien que l'injustice humaine et divine. Fabienne BERCEGOL, à qui l'on doit le très bel ouvrage La Chartreuse de Parme ou la rêverie héroïque, propose une étude consacrée aux Natchez de Chateaubriand (Des "Natchez" aux "Martyrs": violences de l'éros dans l'œuvre de Chateaubriand, pp. 93-108). Elle insiste notamment sur la vision tragique qui domine ce texte. Dans une théâtralisation des perversions de l'éros, nous serait ainsi montrée une humanité livrée au Mal.

Christine MARCANDIER-COLLARD, spécialiste des scènes sanglantes dans la littérature de la première moitié du xix ${ }^{e}$ siècle, livre une belle étude sur l'esthétisation de la violence du monde dans les œuvres de Stendhal et Mérimée. Dans Le Gai savoir romantique de la violence (Mérimée, Stendhal), elle démontre que le rire dans la violence est, chez ces deux auteurs, un geste à la fois politique et esthétique, en ce qu'il est en réalité une subversion critique (pp. 109-118). L'article de Jacques BIRNBERG, "Les Cenci" au confluent des légendes, des mythes et des thèmes romantiques (pp.119-148) vient compléter harmonieusement l'étude de Christine Marcandier-Collard, en adoptant cette fois-ci un angle moins macrostructural. Se focalisant sur la nouvelle stendhalienne Les Cenci, Jacques Birnberg cherche en effet à montrer que ce texte est emblématique des légendes, mythes et thèmes romantiques. Il en serait une condensation d'autant plus forte qu'il est un texte bref.

6 Un important ensemble est consacré à l'omniprésence de la mort et de la férocité humaine dans l'œuvre de Prosper Mérimée. François GÉAL, Thierry OzWALD, Clarisse 
RÉQUÉNA et Joseph-Marc BAILBÉ tendent à souligner dans leurs articles respectifs à quel point l'idée même de violence a été, pour Mérimée, perçue avant toute chose comme une réalité anthropologique. Dans Une poétique du saisissement: les derniers instants du condamné à mort dans la II "Lettre d'Espagne" («Une exécution»), François GÉAL cherche à montrer que l'omniprésence de la mort dans ces pages est notamment liée à la thématique particulière de l'exécution (pp.149-168). Thierry ozWALD, spécialiste du récit bref, propose un article intitulé $L a$ "Chronique du règne de Charles IX": névrose individuelle et psychose collective (pp.167-178). D'après lui, la Chronique du règne de Charles IX ne peut plus être perçue comme une stylisation fantasmatique d'une période historique. Elle serait davantage la manifestation particulière d'une psychose globale. Dans La corrida: une tragédie romantique? Prosper Mérimée à cinq heures de l'après-midi (pp.195-234), Clarisse RÉQUÉNA montre au moyen de nombreux exemples que ce spectacle d'origine espagnole incite, d'après Mérimée, à réfléchir sur l'essence même de l'homme et de la vie. Mérimée tendrait en effet à percevoir l'existence comme un véritable combat à mort sur le théâtre du monde. Joseph-Marc BAILBÉ, pour sa part, s'intéresse dans un bref article à la figure de Don Juan (Le "Don Juan" de Mérimée: la violence et le sacré, pp. 235-242). La violence et le sacré sont mobilisés ici essentiellement dans le but d'établir une critique des Âmes du Purgatoire, récit considéré comme ayant des longueurs et encore trop tributaire d'une vision traditionnelle du personnage de Don Juan.

7 Hélène SPENGLER, dans son article «Barbarus hic ego sum quia non intelligor illis». Stendhal ou l'autre romantisme (pp. 179-194), rappelle les réticences de Stendhal à se complaire dans une écriture de l'horrible. Le recours au sublime lui permet d'établir une distanciation esthétique avec le fait sanglant, ce qui offre à ce dernier la possibilité de conserver une pure beauté énergétique. Suzel ESQUIER développe une analyse similaire à celle d'Hélène Spengler, en abordant la question de la distanciation à partir d'une réécriture stendhalienne du livret d'Otello de Rossini (La mise en scène de la mort dans l'opéra "Otello" de Rossini et ses résonances stendhaliennes, pp. 253-264). Fanny BÉRAT-ESQUIE participe, par son article Baudelaire et Stendhal critiques d'art autour de la figure de Delacroix: le «sauvage» en peinture (pp. 277-288), de l'élargissement de la réflexion à d'autres arts que la seule littérature. Elle établit un lien tout à fait stimulant et intéressant entre Stendhal et Baudelaire. En tant que critiques d'art, tous deux se rejoignent notamment dans leur goût commun pour l'association de la beauté et de la mélancolie. Andrée MANSAU rappelle quant à elle dans son étude Tombes de femmes à Rome (pp. 243-251) l'attrait mélancolique de Stendhal pour la beauté de la mort. On peut regretter que l'article, très bref, ne cherche pas véritablement à mettre en perspective par le biais d'une problématisation forte un relevé par ailleurs précis et intéressant.

8 Cette nouvelle publication des actes d'un colloque s'étant tenu en 2007 avait pour objectif d'éclairer d'un jour nouveau le si fascinant romantisme noir. L'ensemble des études réunies traite le thème avec précision, à de rares exceptions près. La rigueur des analyses constitue la principale force de ces actes. Si les constats sur la surenchère complaisante du sang et de la violence dans les textes littéraires du XIX siècle ou, au contraire, sur la mise à distance sublime ou ironique de ceux-ci ne sont guère novateurs, chaque étude présente des analyses tout à fait stimulantes sur un certain nombre de détails jusqu'alors peu étudiés. Enfin, on peut estimer que cet ouvrage, s'il est censé prendre en considération aussi bien l'œuvre de Stendhal que celle de 
Mérimée, apporte en réalité un complément plus satisfaisant aux études mériméennes qu'aux études stendhaliennes. 